\title{
(DRAFT) \\ SPACE SHUTTLE UHF COMMUNICATIONS PERFORMANCE EVALUATION
}

\author{
Shian U. Hwu, and Yin-Chung Loh \\ Lockheed Martin Space Operations, Houston, Texas 77258 \\ Quin D. Kroll and Catherine C. Sham \\ NASA Johnson Space Center, Houston, Texas 77258
}

\begin{abstract}
An extension boom is to be installed on the starboard side of the Space Shuttle Orbiter (SSO) payload bay for thermal tile inspection and repairing. As a result, the Space Shuttle payload bay Ultra High Frequency (UHF) antenna will be under the boom. This study is to evaluate the Space Shuttle UHF communication performance for antenna at a suitable new location. To insure the RF coverage performance at proposed new locations, the link margin between the UHF payload bay antenna and Extravehicular Activity (EVA) Astronauts at a range distance of 160 meters from the payload bay antenna was analyzed. The communication performance between Space Shuttle Orbiter and International Space Station (SSO-ISS)

during rendezvous was also investigated. The multipath effects from payload bay structures surrounding the payload bay antenna were analyzed. The computer simulation tool based on the Geometrical Theory of Diffraction method (GTD) was used to compute the signal strengths. The total field strength was obtained by summing the direct fields from the antennas and the reflected and diffracted fields from the surrounding structures. The computed signal strengths were compared to the signal strength corresponding to the $0 \mathrm{~dB}$ link margin. Based on the results obtained in this study, RF coverage for SSO-EVA and SSOISS communication links was determined for the proposed payload bay antenna UHF locations. The RF radiation to the Orbiter Docking System (ODS) pyros, the payload bay avionics, and the Shuttle Remote Manipulator System (SRMS) from the new proposed UHF antenna location was also investigated to ensure the EMC/EMI compliances.
\end{abstract}

\section{Introduction}

An extension boom is to be installed on the starboard side of the Space Shuttle Orbiter (SSO) payload bay. As a result, the SSO Space to Space Communication System (SSCS) payload bay UHF antenna will be under the boom. This study is to support relocating the UHF antenna to a suitable new location.

The SSO payload bay UHF antenna is required to provide adequate UHF communication links for Extravehicular Activity (EVA) astronauts. The payload bay antenna pattern will be distorted due to electromagnetic reflection and diffraction by surrounding payload bay structure obstructions. To ensure the RF coverage can meet the system requirements, the link margin evaluation must take into account such antenna pattern distortion. The system must be able to compensate for the distortion of the antenna patterns, and the antenna must provide reasonable gain throughout designated areas of coverage for the communication links to function effectively.

The purpose of this study is to determine the signal strengths and SSO-EVA RF coverage performance for the payload bay antenna at proposed locations. Formerly, conventional antenna pattern prediction was based on full-scale mockup measurements. The large dimensions of a full-scale Space Shuttle mockup requires a large quiet zone for the illuminating field, which leads to high towers and, to a very large test range. Due to reflections of the illuminating waves by the ground and other obstacles, additional measures must be taken to correct and compensate the measured results. In addition to the full-scale mockup test 
technique, one approach to help in solving the measurement problem is using the scale-model mockup technique. This approach has a number of advantages over the full-model measurement technique since it can be performed in an indoor anechoic chamber where the effects of ground are eliminated. It usually gives reasonably accurate data, but still requires a great deal of engineering time and expense for mockup development and testing.

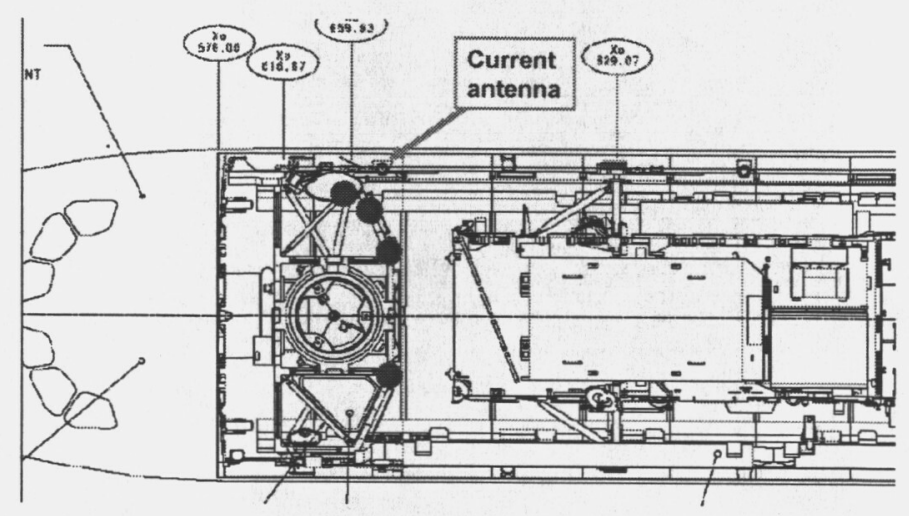

Figure 1. Space Shuttle payload bay configuration.

Another approach in solving the measurement problem is using an electromagnetic modeling technique capable of computing signal strengths in both near-field and far-field ranges [1]. Computer simulation is preferred when (1) it is too expensive and dangerous to perform real tests or experiments on an existing complex vehicle; (2) the vehicle is not available or cannot be tested for a real scenario.

A reliable analytical tool provides matrix comparison for proposed approaches and helps to find the best solutions. Modern high-speed computers with large storage capacity have made possible the theoretical calculation of the radiation pattern of antennas mounted on complex structures such as Space Shuttle. The main advantage of this mathematical method is that, once the geometry of the vehicle has been represented in the computer, the influence of different positions of the individual antennas can be easily evaluated. If the position of an antenna has been selected on the basis of a computer evaluation, the number of measurements can be cut down to a reasonable minimum.
Since the Space Shuttle is large in terms of wavelength, the Geometrical Theory of Diffraction method (GTD) is a suitable candidate for the computational task. The Method of Moments $(\mathrm{MoM})$ is a feasible tool that provides better accuracy. However, excessive computer resources and computing time will be required for electrically large structure models. The MoM technique is suitable to verify GTD results with partial structure models immediate to the antenna. In this study, the GTD was used to compute the electric fields. The total field was obtained by summing the direct fields from the antennas and the reflected and diffracted fields from the surrounding structures. The computed signal strengths were compared to the signal strength corresponding to the $0 \mathrm{~dB}$ link margin. The RF coverage was determined for proposed antenna locations.

\section{Computational Method}

The Geometrical Theory of Diffractions was used in the simulations to take into accounts the multipath effects from the ISS and SSO structures.

\section{a. Assumptions}

It is assumed that the electromagnetic properties of the Space Shuttle payload structures are such that the surfaces are highly reflective at the UHF frequency. Thus, the Space Shuttle and payload bay structures are modeled as perfect electrical conductors.

The SSO payload bay antenna is a quadrifilar helical antenna. The operating frequencies are 414.2 $\mathrm{MHz}$ and $417.1 \mathrm{MHz}$. An average frequency of 415.65 $\mathrm{MHz}$ was used in this analysis.

\section{b. Signal Strength Computations}

At high frequencies the scattering fields depend on the electrical and geometrical properties of the scatterer in the immediate neighborhood of the point of reflection and diffraction. Thus, the total fields $\left(\mathrm{E}^{\mathrm{tot}}\right)$ can be obtained by summing up the individual contributions of the direct field $\left(\mathrm{E}^{\mathrm{dir}}\right)$, reflected field $\left(\mathrm{E}^{\mathrm{ref}}\right)$, and diffracted field $\left(\mathrm{E}^{\mathrm{dif}}\right)$, as following,

$$
E^{\text {tot }}=E^{d i r}+\sum_{n=1}^{N} E_{n}^{r e f}+\sum_{m=1}^{M} E_{m}^{d i f} .
$$


$\mathrm{E}^{\text {tot }}$ : Total field at the observation point,

$\mathrm{E}^{\mathrm{dir}}$ : Direct fields from antennas,

$\mathrm{E}^{\text {ref }}:$ Reflected fields from plates and cylinders,

$\mathrm{E}^{\mathrm{dif}}:$ Diffracted fields from plates and cylinders.

The diffracted fields are related to the incident fields by means of diffraction coefficients; in a similar way the reflected fields are obtained using reflection coefficients. Since the diffracted field is determined solely by the incident field and the local nature of the scattering surface, it is possible to derive a diffraction function relating the incident field to the diffracted field for a certain scatter geometry, a so called canonical configuration. Figure 2 shows ray bounces in the SSO payload bay.

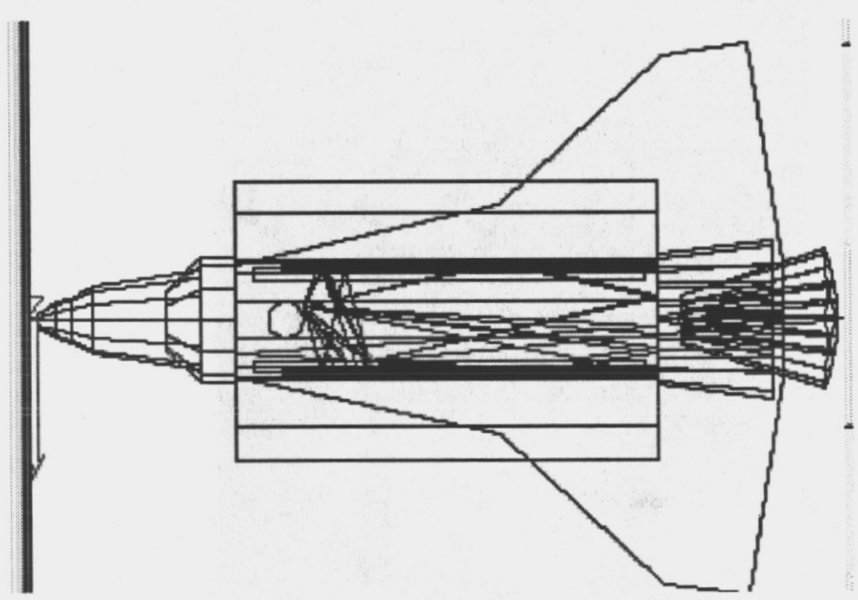

Figure 2. Ray bounces in SSO payload bay.

\section{Proposed Antenna Locations}

The antenna relocation constraints and considerations are (1) Maintain performance of the communication system, (2) Footprint availability for relocation, (3) Maintain structure \& payload minimum clearance requirement, (4) Maintain EMI/EMC requirements.

The communication performance requirement is $90 \%$ coverage for upper hemisphere and suitable for permanent placement of SSOR antenna with low risk. The SSCS must meet the following specification requirements (1) Complying Space to Space Communications System, specification (JSC-27181), (2) Providing RF communication link with ISS during docking operations, (3) Providing RF communication link with EVA crews. In additional, the WVS communication must not be noticeably degraded by interference from SSOR. The RF Keep Out Zone (KOZ) must be maintained.

A total of 25 candidate locations were evaluated by six astronauts in the Neutral Buoyancy Lab (NBL). Initial locations were selected based on communications coverage. Crewmembers performed Orbiter contingency tasks in proximity to antennas and evaluated nominal translation paths. The 8 acceptable locations, as shown in Figure 3 and Table 1, were identified.

General evaluation guidelines are (1)Minimize obstructions in translation paths, (2) Minimize tether snag points, (3) Minimize obstructions for Tool Storage Assembly (TSA) \& Orbiter contingency worksites.

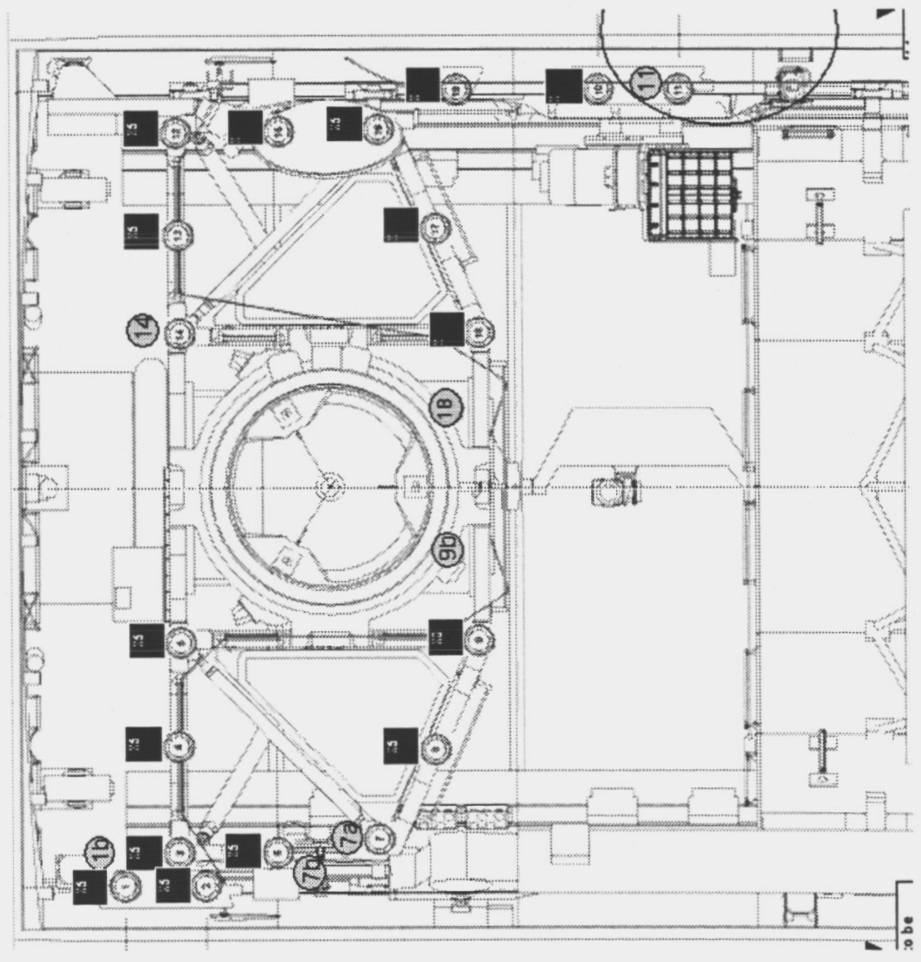

Figure 3. Proposed SSO payload bay UHF antenna locations. 
and data communications between the SSO and the ISS during rendezvous out to a range of $2 \mathrm{~km}$ along the rendezvous profile as defined in the "flight data rendezvous checklist", (JSC-48072)

The link assessment is based on the Circuit Margin Data Book, Revision E, September 9, 2003. A weaker link, which is a link from SSO-to-ISS, is considered. The SSO UHF antenna transmit power is $-3.4 \mathrm{~dB}$ for the low power mode. The high power mode is not considered in the link analysis.

\section{Results And Discussions}

The link margin from the SSO to the ISS primary and secondary strings for two flight configurations, 10A.1 and 16A, for all proposed payload bay UHF antenna locations were computed and analyzed. As shown in Fig. 5, the $2 \mathrm{Km}$ range requirement is met by all proposed antenna locations. The signal degradation at around $4.2 \mathrm{Km}$ is due to the blockage from the ISS structure. The blockage structure was identified to be the Soyuz solar panel. Table 2 shows RF coverage comparison for proposed antenna locations.

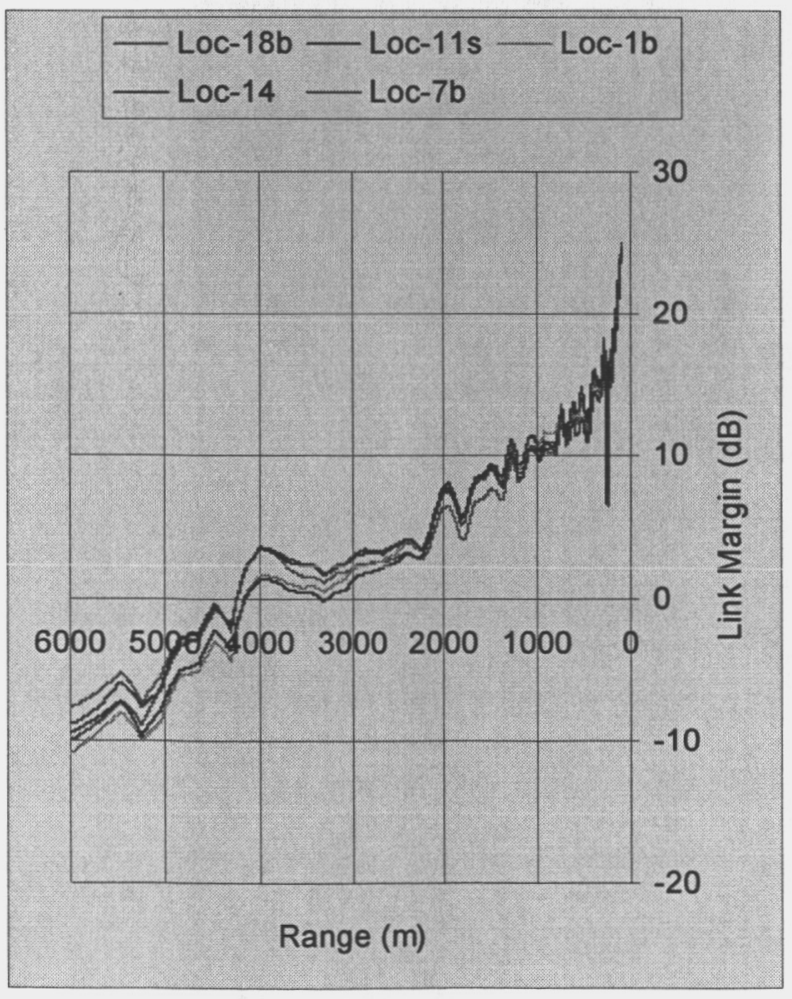

Figure 5. Rendezvous communication coverage comparison
Table 2. Proposed SSO UHF antenna location communication coverage comparison

\begin{tabular}{|l|l|l|}
\hline Antenna & $\begin{array}{l}\text { SSO-EVA } \\
160 \mathrm{~m} \\
\text { Hemispherical } \\
\text { Coverage }\end{array}$ & $\begin{array}{l}\text { SSO-ISS } \\
2 \mathrm{~km} \\
\text { Nominal } \\
\text { Trajectory } \\
\text { Coverage }\end{array}$ \\
\hline $11-$ Starboard & $96 \%$ & $100 \%$ \\
\hline $7 \mathrm{~b}$ & $96 \%$ & $100 \%$ \\
\hline $9 \mathrm{~b}$ & $92 \%$ & $100 \%$ \\
\hline $18 \mathrm{~b}$ & $92 \%$ & $100 \%$ \\
\hline $1 \mathrm{~b}$ & $97 \%$ & $100 \%$ \\
\hline 14 & $96 \%$ & $100 \%$ \\
\hline $7 \mathrm{a}$ & $94 \%$ & $100 \%$ \\
\hline 19 & $96 \%$ & $100 \%$ \\
\hline
\end{tabular}

\section{Antenna Location Selection}

The starboard side location $18 \mathrm{~b}$ was selected for the new Space Shuttle payload bay UHF antenna. This selection was based on the communication performance, the ease of the hardware installation and the cable runs and cable re-usage.

\section{Electromagnetic Compatibility}

\section{a. RF Radiation to ODS Pyros}

This section analyzes the RF radiation to the Orbiter Docking System (ODS) pyros from the new proposed payload bay UHF antenna location.

Based on the Rockwell ODS Pyros test report, the pyros were tested to $166.5 \mathrm{~V} / \mathrm{m}$ at $416 \mathrm{MHz}$ [2]. The shortest distance between ODS pyro and the new proposed UHF antenna location is 1.1 meters. The UHF antenna at new location at the worst case with the maximum transmitting power from the transmitter is $40.2 \mathrm{dBm}$ or $10.4 \mathrm{~W}$ at the high power mode operation can put out $20 \mathrm{~V} / \mathrm{m}$ at closest ODS pyro, as shown in Fig. 6. The electric fields in the payload bay around ODS in X-Y plane at $Z=465$ " are shown in Fig. 7.

The permissible electric field level for ODS pyros at $416 \mathrm{MHz}$ with $16.5 \mathrm{~dB}$ safety margin is 
and data communications between the SSO and the ISS during rendezvous out to a range of $2 \mathrm{~km}$ along the rendezvous profile as defined in the "flight data rendezvous checklist", (JSC-48072)

The link assessment is based on the Circuit Margin Data Book, Revision E, September 9, 2003. A weaker link, which is a link from SSO-to-ISS, is considered. The SSO UHF antenna transmit power is $-3.4 \mathrm{~dB}$ for the low power mode. The high power mode is not considered in the link analysis.

\section{Results And Discussions}

The link margin from the SSO to the ISS primary and secondary strings for two flight configurations, 10A.l and 16A, for all proposed payload bay UHF antenna locations were computed and analyzed. As shown in Fig. 5, the $2 \mathrm{Km}$ range requirement is met by all proposed antenna locations. The signal degradation at around $4.2 \mathrm{Km}$ is due to the blockage from the ISS structure. The blockage structure was identified to be the Soyuz solar panel. Table 2 shows RF coverage comparison for proposed antenna locations.

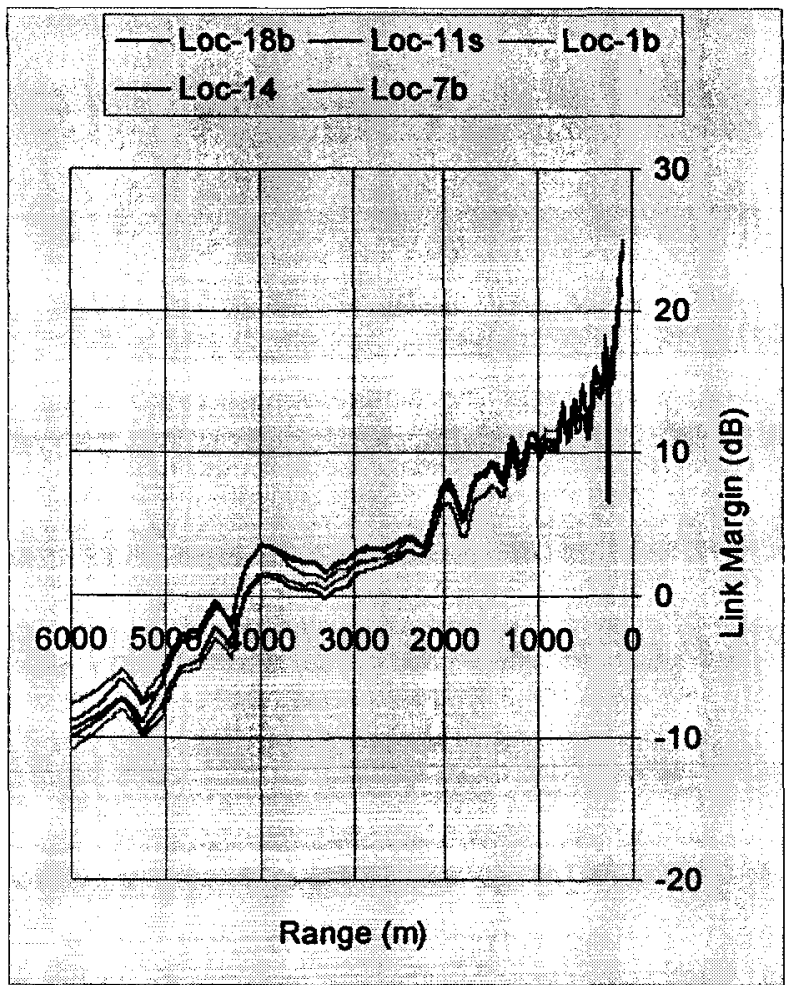

Figure 5. Rendezvous communication coverage comparison
Table 2. Proposed SSO UHF antenna location communication coverage comparison

\begin{tabular}{|l|l|l|}
\hline $\begin{array}{l}\text { Antenna } \\
\text { Location }\end{array}$ & $\begin{array}{l}\text { SSO-EVA } \\
160 \mathrm{~m} \\
\text { Hemispherical } \\
\text { Coverage }\end{array}$ & $\begin{array}{l}\text { SSO-ISS } \\
2 \mathrm{~km} \\
\text { Nominal } \\
\text { Trajectory } \\
\text { Coverage }\end{array}$ \\
\hline 11 -Starboard & $96 \%$ & $100 \%$ \\
\hline $7 \mathrm{~b}$ & $96 \%$ & $100 \%$ \\
\hline $9 \mathrm{~b}$ & $92 \%$ & $100 \%$ \\
\hline $18 \mathrm{~b}$ & $92 \%$ & $100 \%$ \\
\hline $1 \mathrm{~b}$ & $97 \%$ & $100 \%$ \\
\hline 14 & $96 \%$ & $100 \%$ \\
\hline $7 \mathrm{a}$ & $94 \%$ & $100 \%$ \\
\hline 19 & $96 \%$ & $100 \%$ \\
\hline
\end{tabular}

\section{Antenna Location Selection}

The starboard side location $18 \mathrm{~b}$ was selected for the new Space Shuttle payload bay UHF antenna. This selection was based on the communication performance, the ease of the hardware installation and the cable runs and cable re-usage.

\section{Electromagnetic Compatibility}

\section{a. RF Radiation to ODS Pyros}

This section analyzes the $R F$ radiation to the Orbiter Docking System (ODS) pyros from the new proposed payload bay UHF antenna location.

Based on the Rockwell ODS Pyros test report, the pyros were tested to $166.5 \mathrm{~V} / \mathrm{m}$ at $416 \mathrm{MHz}$ [2]. The shortest distance between ODS pyro and the new proposed UHF antenna location is 1.1 meters. The UHF antenna at new location at the worst case with the maximum transmitting power from the transmitter is $40.2 \mathrm{dBm}$ or $10.4 \mathrm{~W}$ at the high power mode operation can put out $20 \mathrm{~V} / \mathrm{m}$ at closest ODS pyro, as shown in Fig. 6. The electric fields in the payload bay around ODS in X-Y plane at $\mathrm{Z}=465^{\text {" }}$ are shown in Fig. 7.

The permissible electric field level for ODS pyros at $416 \mathrm{MHz}$ with $16.5 \mathrm{~dB}$ safety margin is 
$24.9 \mathrm{~V} / \mathrm{m}$. The Space Shuttle Electromagnetic Compatibility Requirement SL-E-0001 Book 2 requires $16.5 \mathrm{~dB}$ margin for ordnance [3]. The $\mathrm{RF}$ radiation from the UHF antenna at proposed new location does not exceed the ODS pyros exposure limit of $24.9 \mathrm{~V} / \mathrm{m}$. The RF radiation from the UHF antenna to the ODS pyros should not be a concern.

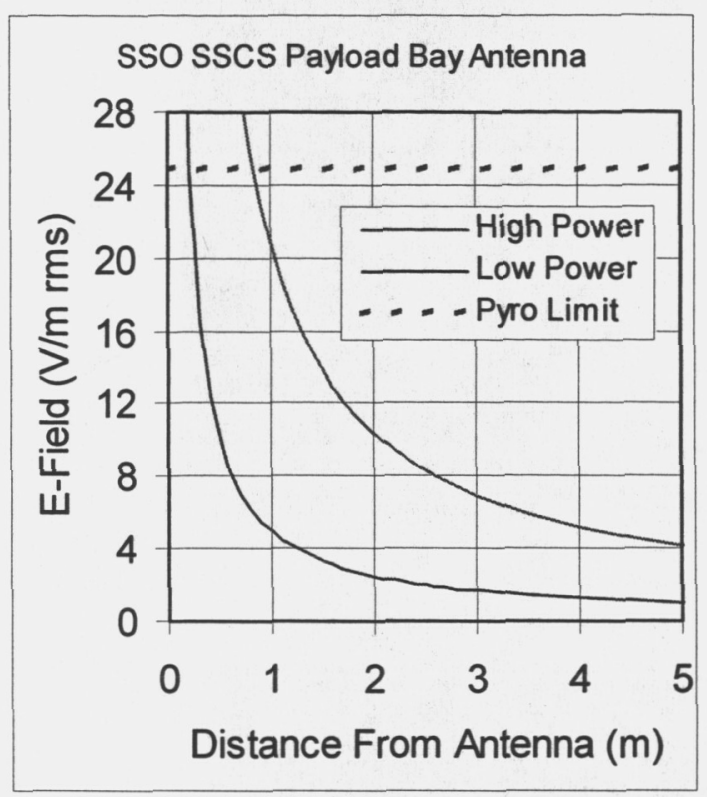

Figure 6. Electric fields (V/m) vs. distances from the UHF antenna.

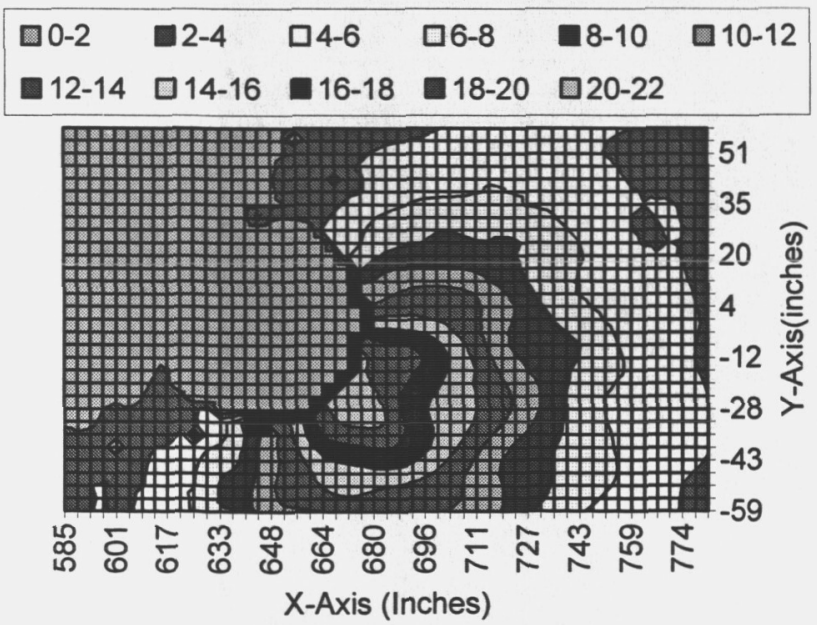

Figure 7. Electric fields $(\mathrm{V} / \mathrm{m})$ in the payload bay around ODS in $X-Y$ plane at $Z=465$ ".

\section{b. RF Radiation to Payload Bay Avionics}

This section analyzes the RF radiation to the existing payload bay avionics box from the new proposed UHF antenna location. Based on the specification document NSTS-21000-IDD-ISS, the permissible electric field level for the Shuttle Orbiter avionics is $4 \mathrm{~V} / \mathrm{m}$ at $413-417 \mathrm{MHz}$ [4]. This $4 \mathrm{~V} / \mathrm{m}$ is to protect payload bay avionics but not the Orbiter structure from RF radiation. The RF radiation from the UHF antenna at proposed new location can be $7 \mathrm{~V} / \mathrm{m}$ at starboard side payload bay liner and is a concern to the Orbiter avionics.

The proposed new antenna location at SSO coordinates of $(684,23,424)$ inches is about 3.6 meter from the nearest avionics box located at (669, $72.6,291.6$ ) inches where is below the payload bay antenna. The UHF antenna gain is $-7.5 \mathrm{~dB}$ at backlobe. The maximum transmitting power from the transmitter is $40.2 \mathrm{dBm}$ or $10.4 \mathrm{~W}$ at the high power mode operation. The electric field level is about $2 \mathrm{~V} / \mathrm{m}$ at the nearest avionics box, as shown in Figure 8. The electric fields in payload bay Y-Z plane at $X=684$ " are shown in Fig. 9. The RF radiation from UHF antenna does not exceed the 4 $\mathrm{V} / \mathrm{m}$ permissible electric field level for the payload bay avionics. The RF radiation to the avionics should not be a concern.

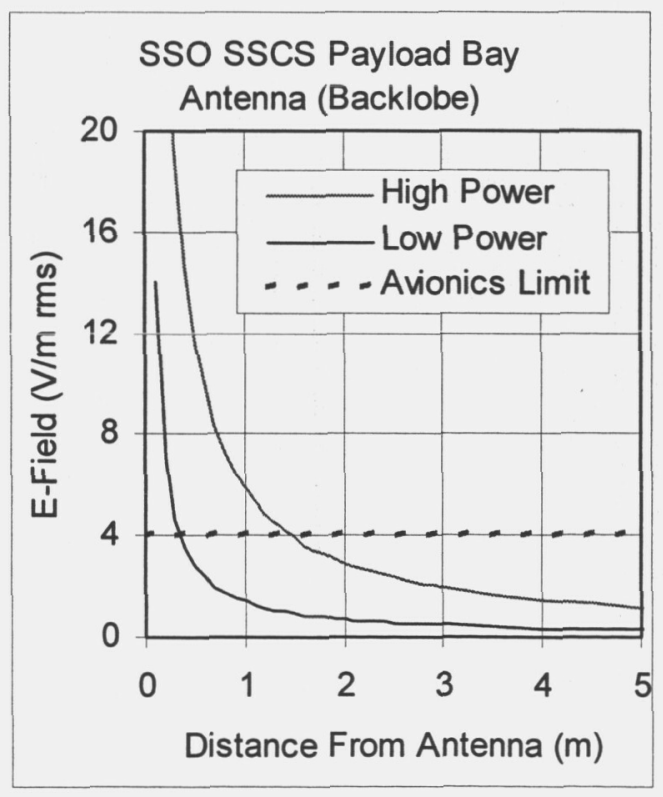

Figure 8. Electric fields (V/m) vs. distances from the UHF antenna. 
E-Field $(\mathrm{V} / \mathrm{m})$ in Payload Bay $\mathrm{Y}-\mathrm{Z}$ Plane at $\mathrm{X}=684 "$

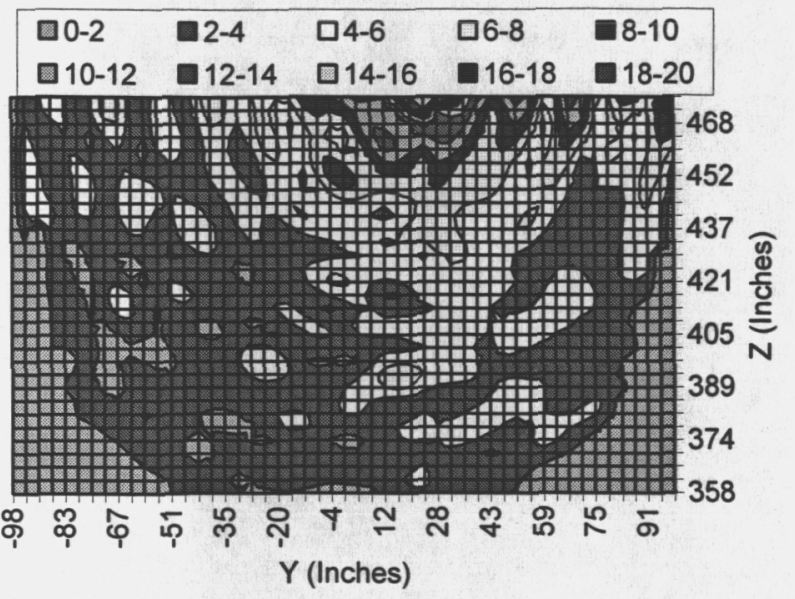

Figure 9. Electric fields $(\mathrm{V} / \mathrm{m})$ in the payload bay $\mathrm{Y}-\mathrm{Z}$ plane at $\mathrm{X}=684$ ".

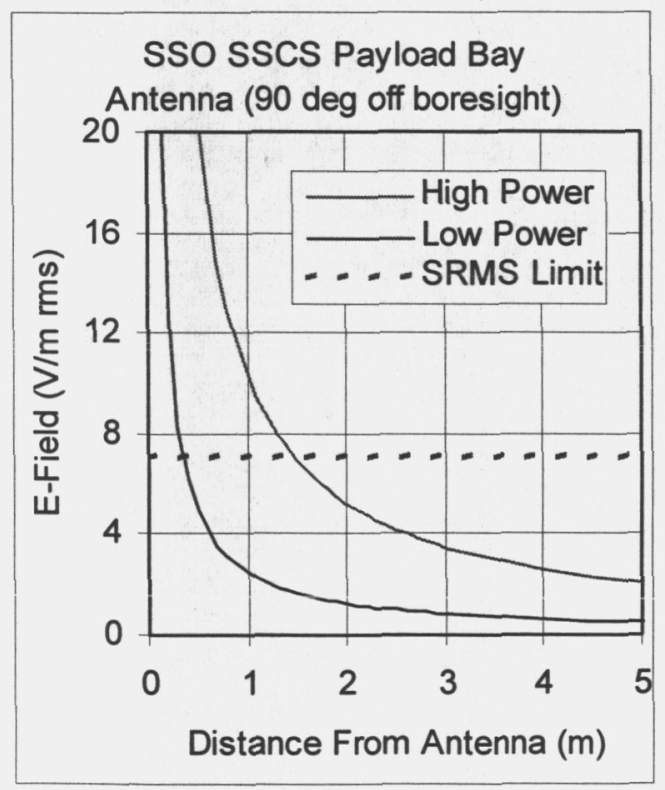

Figure 10. Electric fields (V/m) vs. distances from the UHF antenna.

\section{c. RF Radiation to Payload Bay SRMS}

This section analyzes the RF radiation to the Orbiter Boom/ Remote Manipulator System (SRMS) from the new proposed UHF antenna location. Based on the specification document NSTS-21000-IDD-ISS, the permissible electric field level for Orbiter Boom/SRMS is $7 \mathrm{~V} / \mathrm{m}$ at $413-417 \mathrm{MHz}$. This $7 \mathrm{~V} / \mathrm{m}$ is to protect payload bay Boom/SRMS from RF radiation.

The proposed new antenna location is at (684, $23,424)$. The shortest distance is about 1.3 meter from the starboard boom and is about 2.57 meter from the port SRMS. The payload bay UHF antenna gain is $-2.5 \mathrm{~dB}$ at 90 degree off boresight. The maximum transmitting power from the transmitter is $40.2 \mathrm{dBm}$ or $10.4 \mathrm{~W}$ at the high power mode operation. The minimum circuit loss is 2.1 $\mathrm{dB}$.

The RF radiation from the UHF antenna at the proposed new location can be $8 \mathrm{~V} / \mathrm{m}$, as shown in Figure 8, at starboard side boom and may be a concern to the Orbiter boom. It is recommended to certify the boom to a level $8 \mathrm{~V} / \mathrm{m}$ or higher. The electric field level is about $4 \mathrm{~V} / \mathrm{m}$ at the nearest SRMS, as shown in Figure 10. The electric fields in payload bay $X-Y$ plane at $Z=436$ " are shown in Fig. 11.

SSO Payload Bay Antenna Produced E-Field around SRMS at Z=436"

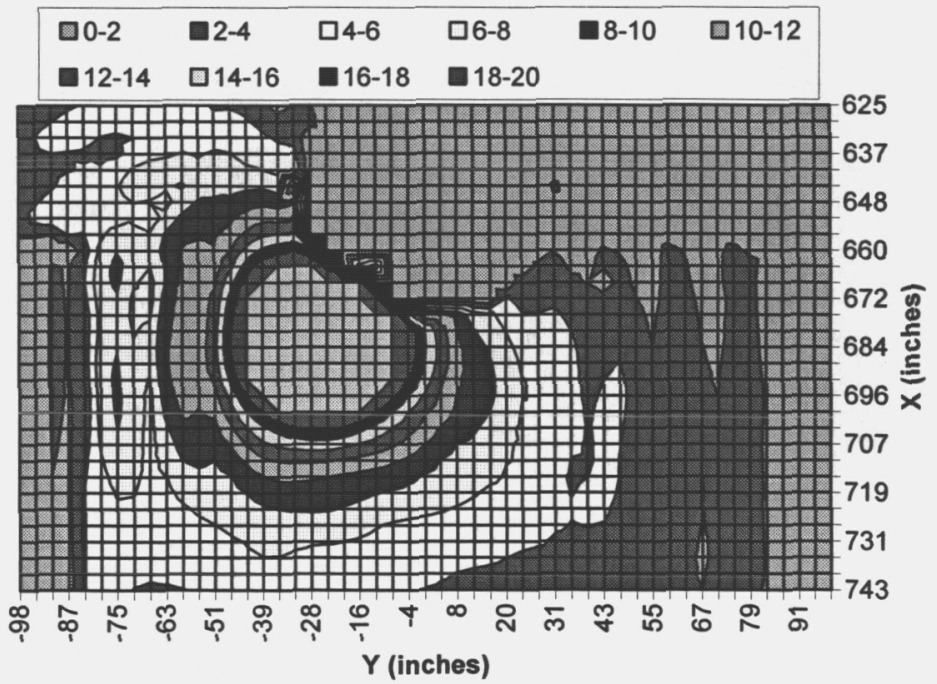

Figure 11. The electric fields $(\mathrm{V} / \mathrm{m})$ in payload bay $X-Y$ plane at $Z=436$ ". 


\section{Conclusions}

In this study, the communication performance for the Space Shuttle Orbiter UHF antenna at a new location was investigated. The multipath effects from payload bay structures surrounding the payload bay antenna were analyzed. The computer simulation tool based on the Geometrical Theory of Diffraction method was used to compute the signal strengths. Based on the results obtained in this study, RF coverage for SSO-EVA and SSO-ISS communication links were determined.

A new antenna location at $18 \mathrm{~b}$ for the Space Shuttle payload bay UHF antenna was selected based on the communication performance, the ease of the hardware installation and the cable runs and cable re-usage. The simulation results indicate the proposed location at $18 \mathrm{~b}$ can meet or exceed the communication performance requirements. The RF coverage in the upper hemisphere is better than $90 \%$ for EVA astronauts at a range of 160 meters. The range distance is much better than $2 \mathrm{Km}$ for the Space Shuttle and Space Station communications during rendezvous operations.

The RF radiation to the Orbiter Docking System (ODS) pyros, the payload bay avionics, and the SRMS from the new proposed UHF antenna location is also investigated to ensure the EMC/EMI compliances.

\section{References}

[1] Shian U. Hwu, Yin-Chung Loh, John P. Boster II, Antha A. Adkins, Catherine C. Sham and Quin D. Kroll, "Space Station Communications Performance Analysis For Mission Support," Proceedings of IEEE VTC 2002, the 2002 Annual International Vehicular Technology Conference, Vancouver, British Columbia, Canada, Sept. 24-29, 2002, Page(s): 1973 -1977.

[2] "Docking Mechanism EED Qualification RF Safety Test," ML0799-5301-002, Rockwell

International, Sept. 2, 1994.

[3] "Space Shuttle Specification Electromagnetic Compatibility Requirement," SL-E-00001-Book 2.

[4] NSTS-21000-IDD-ISS, "International Space Station Interface Definition Document," February 18, 1998.

\section{Disclaimer}

This work was sponsored by NASA Contract NAS9-19100 from Johnson Space Center. The authors would like to thank Tony Tran for his contributions.

\section{Email Addresses}

Shian.u.hwu1@jsc.nasa.gov 